\title{
As ilusões no progresso, as ilusões na democracia burguesa e as mulheres iludidas
}

\author{
Carta de Helena Silvestre ${ }^{1}$
}

Resumo: A autora a partir de sua trajetória militante e pessoal, esboça em sua carta, sua leitura sobre a história das classes sociais no Brasil, a partir da sua interpretação da formação social brasileira e do desenvolvimento (desigual e combinado) do capitalismo periférico brasileiro. A partir de um recorrido histórico que remonta os séculos XX e XXI, a autora indaga sobre como a colonização e a escravidão, a superconcentração da propriedade da terra, a migração e a urbanização acompanhada da industrialização tardia, influem e refletem as especificidades da questão racial no Brasil, escamoteada pelo mito da democracia racial. Na segunda metade da carta, a autora faz uma análise crítica das organizações de esquerda e das experiências dos governos progressistas no Brasil, apontando os limites e contradições do progressismo político institucionalizado e a corrosão da confiança nas instituições democráticas, expressos nas jornadas de junho de 2013 no Brasil. Na última parte da carta a autora indaga sobre o protagonismo das mulheres nos processos políticos contemporâneos, e sobre a ilusão no Estado e na democracia burguesa e na equivocada ideia de progresso, sustentada pela esquerda institucionalizada na América do Sul.

Palavras-chave: Capitalismo-Periférico; Reformismo; Esquerda.

${ }^{1}$ Helena Silvestre é militante do movimento Luta Popular, feminista afroindígena, editora da Revista Amazonas. TAE na Universidade Federal de São Paulo e graduanda pela Universidade de São Paulo. Autora do livro "Do verbo que amor não presta" publicado pela editora Ciclo Continuo como parte do Selo Sarau do Binho de autores periféricos. helenitaluta@gmail.com. 
São Paulo, 14 de agosto de 2018.

Marx meu caro, eu fiquei arrodeando em volta da luz, igual a uma mariposa, buscando um jeito de lhe redigir essa comunicação epistolar. Todos sabemos o quanto você às vezes sabe ser bastante rude e eu mesma já levei alguns bons trancos com as suas grosserias. Mas, entendendo esse jeito bastante brucutu alemão, super europeu e macho, seguimos amigos e é por isso que tomarei a liberdade de lhe perguntar sobre uma coisa que tem ocupado meus pensamentos e creio que só a filosofia marxiana pode me ajudar.

Enveredei recentemente para uma atuação política que privilegia em minha práxis a organização da luta pela emancipação das mulheres nos marcos que você bem sabe, mas prefiro ainda assim, abrir um largo parêntese - sabendo que você também abusou vez ou outra das notas de rodapé - para lhe detalhar melhor.

\section{O recorrido histórico}

Eu sou uma mulher de origem negra e indígena, filha de trabalhadores nordestinos que migraram para o sudeste em busca de trabalho e expulsos das terras que habitavam por diversos motivos como a fome, a miséria, a mecanização agrícola, o latifúndio, enfim. Nordestinos que migraram para São Paulo no auge do processo de industrialização e urbanização que se desenvolveram tardiamente no Brasil, mas em curto período de tempo, provocou verdadeiras transformações na dinâmica social do país e em nossas vidas.

Demorei muito tempo a reconhecer-me como negra, porque embora o capitalismo Brasileiro tenha como seu primeiro alimento o sangue dos milhares de negros e negras sequestrados da África e escravizados aqui, embora o Brasil seja o país com maior população negra ou afro descente fora da África, é um país marcado pelo racismo baseado num mito: o mito da democracia racial que esconde o fato 
de que a miscigenação ocorrida aqui se deu inicialmente com base na violência, no estupro e na escravidão.

A história da colonização brasileira, que é também a história da escravidão, que é também a história da superconcentração da propriedade da terra, que é também a história das classes sociais no Brasil, é a seu tempo a história deste país e de seu povo.

A costa brasileira foi o lugar por onde chegaram os colonizadores, o lugar por onde chegaram os escravos e, por ser a entrada e saída para o mar, foi o lugar onde se fundaram as primeiras cidades e, no nordeste, há diversas delas que foram de enorme importância.

Estas cidades funcionavam como ponto de apoio para o saque das riquezas nacionais pelos europeus, para a chegada dos navios negreiros e também como centros administrativos do domínio colonial sobre todas as terras, sobre todas as propriedades - incluindo nossas vidas - e para a organização do massacre a toda vida que resistisse a tornar-se propriedade, como os milhões de indígenas assassinados durante centenas de anos e até agora.

Quase todos os brasileiros que conhecem um pouco de sua ascendência indígena, poderiam lhe contar o que eu posso: que uma indígena ancestral minha foi caçada na mata, por portugueses, com cachorros e pistolas, e depois estuprada, sequestrada e escravizada. Como também quase todos os brasileiros poderiam lhe contar de algum avô distante que trabalhou nos canaviais para enriquecer os países imperialistas enquanto sua companheira, além de ser escrava, era estuprada pelo seu senhor e dono branco.

A miscigenação aconteceu, é verdade. Mas ela não se construiu na "cordialidade" do povo brasileiro, ela foi produto das mais brutais violências. E aqueles e aquelas, filhos de indígenas e negros escravizados e mais tarde libertos, são o que podemos chamar de classe trabalhadora brasileira, que também tem sangue branco, é verdade.

Os negros e os indígenas escravizados trabalhavam nas lavouras e terras que eram propriedade total dos colonizadores. Alimentandose do trabalho não pago e da fértil terra gratuita que nos foi roubada, 
os colonizadores adquiriram o capital primário para mais tarde se converterem em capitalistas e originaram a burguesia brasileira assim como também sustentaram muitas burguesias em outras partes do mundo.

Houveram resistências, ocorreram levantes e revoltas que são parte dessa luta incansável que o povo levou adiante pela sua liberdade. Quase todas elas foram afogadas no sangue da repressão brutal e assassina e, num país tão extenso territorialmente, quase nenhuma conseguiu organizar-se como um levante nacional.

Houveram ainda resistências culturais: hábitos, artesanatos, instrumentos, cantos, costumes, comidas e palavras que os filhos dos escravos guardavam em suas vidas como forma de não se esquecer de onde vieram; a capoeira, o batuque, o samba, as cirandas, a feijoada, o candomblé e tantas coisas que até hoje sobrevivem e constituem nosso riquíssimo panorama cultural e são também transformadas em mercadorias e arrancadas de nós, seus produtores.

A libertação dos escravos não foi, contudo, acompanhada da libertação da terra, da libertação da riqueza e nem da libertação da vida. Por necessidades impostas também desde o império, o Brasil se tornou independente sem nenhuma guerra de libertação nacional e os escravos foram libertos quando já se alcançava um plano infalível para mudar sua condição jurídica - tornando-os livres - sem contudo mudar sua condição econômica, mantendo-nos assim, aprisionados ao trabalho mal pago, ao trabalho precário.

A terra, mantendo-se super concentrada, seguiu sendo um dos principais ativos do nascente capitalismo brasileiro e, depois dos canaviais, vieram a extração de ouro, de pedras preciosas, vieram os cafezais e a pecuária. Estes foram os motores da acumulação de capital - junto com a escravidão concomitante a alguns deles - desde o “descobrimento do Brasil" até o final do século XIX.

Os escravos libertos não tinham nenhuma terra onde trabalhar ou morar, os escravos libertos não tinham nenhum meio de produção que pudesse lhes servir para produzirem seu sustento, os escravos libertos tinham liberdade, fome e miséria.

$92 \quad$ As ilusões no progresso, as ilusões... 


\section{$\mathrm{O}$ século $\mathrm{XX}$}

No início do século XX a centralidade econômica do país havia se deslocado para o sudeste que, ainda baseado na produção agroexportadora, mantinha como em todo território nacional, a concentração da terra.

Os escravos libertos procuravam agora migrar para lugares onde pudessem encontrar algum trabalho, e teve início aí uma das maiores movimentações populacionais que o Brasil já viu. Uma verdadeira diáspora que punha milhões de pessoas a deslocar-se territorialmente para as cidades em busca da sobrevivência. E em algumas décadas, entre 1930 e 1970, o Brasil passou de majoritariamente rural a majoritariamente urbano.

As cidades que se fundaram com a colonização se transformaram em pontos de apoio para um processo tardio de urbanização e industrialização que se generalizaram baseadas no trabalho precário, nos baixos salários e no crescimento populacional caótico do que viriam a ser depois grandes centros urbanos como a metrópole São Paulo.

Apartados da terra, apartados de meios de produção de suas necessidades vitais, considerados sub-humanos, sub-brasileiros, sub-trabalhadores pela sua descendência, os escravos libertos e seus descendentes forneceram a mão de obra que a nascente industrialização precisava para se desenvolver.

E, migrando para onde esta indústria se instalava, adensaram a região litorânea produzindo junto com a industrialização e urbanização formais, a urbanização informal, ilegal, clandestina, caótica e precária, desprovida de serviços, majoritariamente negra e muito pobre.

Embora se industrializasse - de maneira tardia, marginal e dependente - o Brasil nunca deixou de ser, na Divisão Internacional do Trabalho, a fazenda do mundo, mantendo um padrão de industrialização que acolhia a linha de produção mais tóxica ou que menos agregava valor ao que produzia. 
Para que a industrialização tardia se desenvolvesse, era necessário explorar também mão de obra com algumas qualificações que os filhos dos escravos não tinham e, trabalhadores europeus de "segunda classe", sobretudo de países europeus mais pobres - como a Itália - ancoraram também neste país.

Um país como onosso, colonizado, dependenteeeconomicamente subalterno em relação aos países de capitalismo central, padece de um modelo de desenvolvimento econômico que pode ser descrito como desigual e combinado.

Desigual porque, se estrutura na escravidão e em formas arcaicas de propriedade da terra e de organização social do trabalho e, combinado, porque é exatamente este modelo a essência da lucratividade que permitiu saltos fenomenais no desenvolvimento da tecnologia, na organização produtiva e no "progresso" dos países imperialistas.

É desigual e combinado porque acolhe a ocorrência simultânea de aspectos avançados e atrasados no processo de desenvolvimento econômico; um setor extremamente moderno da economia pode existir de forma combinada com o mais atrasado e assim a nossa urbanização convive com uma forma de apropriação da terra que remonta a colonização, a nossa industrialização convive com um traço de superexploração do trabalho que remonta a escravidão, etc.

De rural a urbano, de escravo liberto a trabalhador aprisionado, do interior para o litoral, do campo para a cidade, da terra para as fábricas. Seria impossível imaginar que transformações tão profundas concentradas em poucas décadas ocorressem sem conturbações enormes.

Tudo isso forjou uma enorme e complexa concentração populacional urbana de trabalhadores pobres, majoritariamente migrantes, não brancos, superexplorados e os choques e atritos produziam um caldeirão de insatisfação, revolta, violência e precariedade.

94 As ilusões no progresso, as ilusões... 
$\mathrm{Na}$ esteira deste processo, foram surgindo organizações de trabalhadores - influenciadas também pelas tradições de organização sindical trazidas pelos trabalhadores imigrantes - partidos, como o partido comunista, associações e movimentos que lutavam por reforma agrária e por melhores condições de vida nas concentrações populacionais mais pobres das grandes cidades.

Este caldeirão foi abafado pela ditadura militar que, valendose da violência e de um sofisticado e extremamente concentrado monopólio de comunicação privado, fez o povo amargar mais décadas de desgraça e crescimento econômico, de mais urbanização e menos direitos, de mais industrialização e nenhuma democracia.

As organizações de luta dos trabalhadores foram caladas, reprimidas, destruídas e, com o passar do tempo, tiveram de se reinventar. Atuando na clandestinidade ou na guerrilha, amadureceram junto com esse enorme contingente de homens e mulheres trabalhadores que, nos anos 70 começavam a sentir os efeitos da crise econômica estrangulando ainda mais suas vidas.

\section{A esquerda, a ditadura e a democracia da colaboração entre classes}

Foi assim que essa esquerda, aos poucos e amparando-se nas lutas contra os ataques a direitos que aconteciam como produto da crise, ganhou força, ganhou corpo e organizou no final dos anos 70 e início dos anos 80 algumas de nossas mais importantes greves e lutas, constituindo um sentimento e uma identidade da classe trabalhadora no Brasil.

A ditadura foi se tornando insustentável e caiu pela força dos trabalhadores que conquistaram a democracia. Mas a democracia conquistada era muito parecida com o mito da democracia racial: nos deu direitos políticos mas não tocou nas estruturas econômicas, nos deu igualdade jurídica e opressão e exploração na vida concreta. 
Com a queda do muro, a esquerda desnorteada foi se institucionalizando, foi perdendo a sua radicalidade, afastando-se da classe trabalhadora que, nos anos 90 padeceu a chaga da implantação neoliberal na América Latina. E explodiram as chacinas, o desemprego, a violência e caos urbanos, o descrédito nas instituições do Estado e nessa própria democracia, ainda mais assassina que a ditadura.

Foi neste momento que a direita, necessitando de fôlego novo, associou-se a setores dessa esquerda e produziu uma grande ilusão que foi um governo de colaboração entre explorados e exploradores, um governo de união entre filhos de escravos e filhos de senhores de escravos.

O Brasil caminhou por mais de uma década pelas veredas de certa estabilidade econômica mundial que permitiu aos governos realizar a distribuição de migalhas, ou ampliar a possibilidade de consumo via ampliação do mercado de crédito e do endividamento de trabalhadores mais pobres. Anos de aparente apatia que, no entanto, ocultavam uma revolta densa e estruturante que se foi cozinhando subterraneamente.

A maior parte da esquerda, como já dito, distanciada de uma prática de construção orgânica desde as raízes, se perdia em lamentáveis concepções superestruturais e bradava aos quatro ventos seus lindos projetos para os mais pobres (nunca com os mais pobres), esperando que ao toque de sua sineta, a razão ocidental se derramasse como uma chuva de clarividência sobre o povo ignorante e o transformasse numa massa de soldados que pudessem lhes seguir, a eles e a seu projeto "revolucionário".

Enquanto isso, nas favelas onde vivemos, embora tenhamos podido adquirir geladeiras e eletrodomésticos em geral, seguimos sendo - como povo negro - assassinados aos milhares, integrando cifras tão assustadoras como as apresentadas por países em guerra: sim, a guerra aos pobres nunca cessou no Brasil e, institucionalizada de todas as maneiras, foi mantida por todos os governantes, por ação ou omissão.

\begin{tabular}{l|l}
\hline 96 & As ilusões no progresso, as ilusões...
\end{tabular} 
Enquanto a política nacional de habitação nos levava como gado para as baias dos bancos que até hoje devemos - porque não foi como direito e sim como mercadoria que esta política se implementou para favorecer banqueiros e empreiteiras envolvidas nos escândalos de corrupção que englobam todos os partidos no parlamento hoje - os números do feminicídio só aumentaram e os recursos para a implementação das políticas de proteção às mulheres, como a lei Maria da Penha, eram ano após ano subtraídos até sobrar apenas o discurso, que também nos traiu na Carta Ao Povo de Deus.

Enquanto isso, ao mesmo tempo em que acessamos pela primeira vez - nós pobres - o ensino superior, éramos parte dos cifrões que engordavam os barões do ensino privado no Brasil, porque não foi como política pública e direito que acessamos à educação universitária, foi como consumidores de uma mercadoria financiada pelos bancos a juros altíssimos.

Enquanto comprávamos carros à prestação em uma economia emergente completamente dominada pelo neoliberalismo com discurso progressista, humanizado e vermelho, o agronegócio destruía a Amazônia, assassinava indígenas e Quilombolas, exterminando povos que só existem porque muito brava é sua resistência e vem de mais de 500 anos.

Nestas condições, o aumento real dos empregos formais era comemorado ao mesmo tempo em que trabalhadores mais pobres eram empurrados pela especulação imobiliária para os confins das metrópoles, aumentando em muito o tempo de deslocamento de casa para o trabalho, em metrópoles colapsadas pelo trânsito onde, a exemplo de São Paulo, os moradores das regiões periféricas da cidade gastam mais do que 3 horas para trabalhar: a Zona Leste em média é de $3 h 26 .{ }^{2}$

${ }^{2}$ Pesquisa de Mobilidade Urbana, 2017 - Rede Nossa São Paulo. 


\section{Foi então que Junho aconteceu}

Se você conversar com qualquer ativista brasileiro e lhe perguntar um pouco sobre o atual desenho da conjuntura, ao lhe responder, em algum momento, ele lhe falará sobre as Jornadas de Junho de 2013. Falará sobre isso referindo-se às multitudinárias manifestações de rua que aconteceram naquele mês e naquele ano, impulsionadas pela batalha contra o aumento das tarifas de transporte coletivo mas que, ao final, terminaram sendo os maiores protestos de rua desde os anos 80 neste país e exigiam não apenas a redução das tarifas mas transformaram-se num coro imenso que denunciava o quanto a vida dxs mais pobres moradores das metrópoles brasileiras havia atingido níveis de insuportabilidade que explodiram nas ruas.

Junho mudou tudo e ele ainda ronda, como um fantasma, toda a revolta que brota nesse nosso chão.

Há uma série de avaliações sobre o significado daquelas lutas e do que elas trouxeram consigo, eu, obviamente, falo desde o meu olhar.

Junho negava tudo e apontava uma corrosão silenciosa da confiança nas instituições democráticas que voltou a se aquecer em fogo lento durante anos de aparente bonança econômica. É verdade que houveram mudanças na situação econômica das famílias mais pobres, já falei sobre isso. E, no entanto, junho era exatamente uma rebelião negadora de tudo porque diante de sua melhora econômica essas mesmas pessoas se viram ainda subjugadas em seus territórios em detrimento de um tratamento VIP dado por quase todos os governos progressistas deste continente ao agronegócio e ao capital internacional associado à exploração petrolífera, mineira, madeireira, de gás e outras.

Diante dessa melhora econômica, esse povo foi experimentando o que é a vida num liberalismo que nos permitiu algum consumo - nada em comparação aos países de capitalismo central - ao mesmo tempo em que nos envenenou por todos os poros, deixando-nos sufocar.

\begin{tabular}{l|l}
\hline 98 & As ilusões no progresso, as ilusões...
\end{tabular} 
Há muita gente de esquerda no Brasil, que responsabiliza as jornadas de junho e aqueles que não votam pelo fato de que governos traidores perderam seus mandatos para canalhas de direita. Eu me pergunto se em algum momento eles tentaram se colocar no lugar daqueles que ouviram - primeiro da boca de "seus representantes democrático-populares" - sobre a urgência de realizar reformas como a da previdência, já em 2004.

Eu mesma já fui criminalizada por estes partidos quando no governo, aliás, eu e muita gente que seguiu pela via da luta direta como palco principal da nossa luta para além do capital e ainda assim, tanta gente agora parece esquecer tudo o que houve... como se fosse possível esquecer.

Eu não me junto a nenhum coro punitivista mas, ao mesmo tempo, passo longe de qualquer política que alimente tentar manter de pé as ilusões que estão se desmanchando. Assim como tampouco me entrego a qualquer atalho de repetição farsesca que só se viabiliza se eu apagar as minhas próprias rupturas políticas, a minha própria trajetória militante, pois do contrário seria hipócrita e reivindicaria para o mundo aquilo com o qual rompi.

Sou militante há quase duas décadas e, embora seja relativamente jovem, cresci militando e em contato com vários desenhos que essa forma "esquerda" tomou para si ao longo dos anos aqui no Brasil, com especial relação com São Paulo, que é onde vivo e mais intervenho.

De alguns anos para cá, tenho sentido o desgaste de minha identificação com essa palavra "esquerda" embora ainda a use muitas vezes, por facilidade.

Quando Junho de 2013 explodiu nas ruas, surpreendendo a todos nós com sua fúria um tanto desorientada e radical, esse bloco constituído por ativistas que se dedicam há anos a organizar lutas, ficou paralisado pelo fato de que aquilo que explodia nas ruas não possuía os contornos clássicos que sempre gostaram de imaginar e nem as usuais características com que estiveram acostumados. 


\section{Das semelhanças na desgraça continental}

No mês de junho deste ano, 2018, estive na cidade de Buenos Aires, onde outro junho explodia, dessa vez encarnado nos corpos rebelados das mulheres lutando nas ruas pela legalização do aborto. Viajei para estas terras irmãs mesmo no frio intenso porque me aquecia essa atmosfera verde e a tarefa de estar na atividade de lançamento da Revista Amazonas nesta cidade, irmanando-me com mulheres vindas de distintas partes de nossa América - tão subjugada, saqueada e oprimida - a tecer desenhos de novas possibilidades transformadoras que possam outra vez alargar a visão tão estreita que nos impõem esse mundo caduco.

As pessoas de minha família ou de onde cresci nunca saem do próprio país e eu, enxergando o privilégio que tenho de fazê-lo, sempre procuro apreender o quanto mais puder e aprender coisas com os povos de outro lugar.

Estive em um debate que convidou quatro lideranças argentinas com diferentes posições naquilo que convencionamos chamar esquerda (haja paciência) para discutir a conjuntura, seus desafios e as alternativas e estratégias por construir.

Uma posição generalizada enchia a boca de todos para declarar, em bom som, a aposta de todas as suas fichas nas eleições; kirchneristas e peronistas unidos dizendo que o Fora Macri deverá ser construído nas urnas, sob o risco de não ser legítimo (nem sei o que dizer sobre isso).

Me impressionou a semelhança com o discurso da parcela muito grande da esquerda brasileira em relação a Michel Temer e o árduo trabalho de reerguer as ilusões apontando a esperança para o pleito eleitoral de outubro no Brasil.

Há dias de um junho verde, de um tsunami verde que tomou as ruas e arrancou uma primeira grande vitória pela legalização do aborto, um representante dessa esquerda argentina institucionalizada que se arvora a falar em nome de um movimento popular, declara-se então contra a legalização do aborto por ser amigo do papa e faz questão de 
frisar que se não fosse a atuação de parlamentares peronistas, as ruas não surtiriam efeito.

Aí é onde o reformismo - que recua diante do estreitamento de horizontes dos mais oprimidos e explorados pela narrativa capitalista de que a revolução é impossível - se escora num discurso possibilista onde qualquer coisa é melhor que o horror fascista e o horror fascista está mesmo sempre è porta (embora esqueçam que também nos rondou por todos estes anos em que os grupos de extermínio deram fim aos nossos filhos e em que vários dos que agora alertam para o terror sentavam nas cadeiras do poder executivo declarando policiais assassinos como artilheiros no momento de um pênalti).

Este reformismo incorporou a equivocada ideia do progresso que é, em última análise, a perspectiva da "evolução natural" da sociedade num rumo gradualmente positivo, rompendo com a revolução como caminho de interrupção da engrenagem perversa que aniquila nossas vidas e toda a vida no planeta.

Este reformismo, que brada aos quatro ventos a defesa da democracia, é o mesmo que muitas vezes se utiliza da chacota ou das mentiras para desmoralizar mulheres militantes com as quais eles possuem diferenças políticas e teóricas, um reformismo que, embora não assuma, bebeu bastante do estalinismo e seu pensamento único.

Assim, quem não apoia o reformismo, a social-democracia-tardia e os caminhos institucionais, é taxado como colaborador no avanço da direita (tenho até vergonha de escrever isso a você, que tanto nos ensinou sobre dialética).

Não é circunstancial que a mesma esquerda que se lança inteira a alimentar ilusões no estado burguês, comporte também opiniões como esta acerca da legalização do aborto, dado que, na prática deles se enxerga uma visão em que o povo é um monstro ignorante que precisa ser tangido pelos clarividentes salvadores - em geral homens, brancos e, muitas vezes de classe média - por um caminho a salvo do ataque dos monstros fascistas que compunham governos com eles alguns anos atrás. 
É porque não acreditam que o povo seja capaz de ver além de eleições e slogans, é porque se veem tão acima das contradições de que padecemos todos nós - e os protestos, e os rolezinhos, e a ocupação das escolas, e as Jornadas de Junho, e a greve dos garis, e as greves gerais sob governos de direita depois destes terem ganhado nas urnas ou no tapetão e as Greve dos Caminhoneiros - que raciocinam que, já que não podem eles realizar uma mudança estrutural (substituindo a ruptura que precisa ser construída e realizada pela classe trabalhadora) ela não ocorrerá e é melhor salvaguardar-se do pior (elegendo sempre a mediocridade do menos pior).

É porque não podem crer que a mobilização de um setor tão oprimido, violentado e explorado como as mulheres possa ter força para conquistar o que eles em anos de governo nunca nos proporcionaram em nome das "governabilidades".

\section{A reflexiva pergunta}

Já me habituei ao fato de ser chamada de radical, de esquerdista e etc. Já me habituei ao fato de que parte importante daqueles que se reivindicam de esquerda enxergam apenas dois estreitos caminhos que surgem de análises nada dialéticas. Já me habituei também com o fato de que não agem como se vissem nos trabalhadores e trabalhadoras sujeitos da revolução que hoje necessitamos mais ainda do que antes. Mas, diante de tantos levantes protagonizados por mulheres exploradas e oprimidas em todo o mundo, que são empurradas a lutar por não suportarem mais a condição que nos impõem sobreviver, $\mathrm{o}$ que não consigo compreender, meu velho Marx, é como podem haver mulheres - que se declaram revolucionárias e feministas - atuando em seus ativismos para fortalecer essas representações, fortalecendo esses "líderes" e esses projetos que tão pouco nos ofereceram por tanto tempo?

Enfim, não deveria ocupar seu tempo com essas mediocridades, só lhe envio mesmo a carta porque não saberia por onde começar 
para redigir-lhe uma nova missiva. Além do fato de que não possuo muitas novidades e a vida continua bastante parecida com o que lhe contei cartas atrás: lamentavelmente trabalhando todos os dias (reivindico para lhe provocar o belo texto de seu genro), estudando mal e porcamente, me dedicando um pouco à militância e seguindo com as publicações da Revista Amazonas. Aliás, diga a Jenny que não me mande o texto que publicaremos dela muito em cima da hora, precisaremos traduzir do inglês (que você sabe, para mim é grego) e depois eu o passarei ao espanhol.

Um abraço velho urso

Não seja rabugento na sua resposta

Abraço também na Lenchen, nas meninas, no Engels e no Biblioteca.

P.S. te deixo com esse trechinho lindo com o qual topei outro dia. Tenho dito a você; esse Benjamin é uma grande figura humana.

"O caráter destrutivo não vê nada de duradouro. Mas, por isso mesmo, vê caminhos por toda a parte. Mesmo onde os demais esbarram em muros, ou montanhas, ele vê um caminho. Mas porque vê caminhos por toda a parte, também tem que abrir caminhos por toda a parte"

O caráter destrutivo, de Walter Benjamin 
